\title{
Is there still a place for transcranial Doppler in patients with IABP?
}

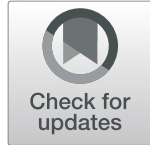

Juliana R. Caldas ${ }^{1,2,3}$, Ronney B. Panerai ${ }^{4,5}$, Rogério Passos ${ }^{1}$ and Ludhmila A. Hajjar ${ }^{6,7^{*}}$

Transcranial Doppler (TCD), a relatively inexpensive and noninvasive tool, is often used to identify emboli, stenosis, vasospasm, brain death, and cerebral autoregulation (CA) [1]. When monitoring patients with intra-aortic balloon pump (IABP), the largest study published with TCD did not show neurological complications or deterioration of CA [2], but the occurrence of abnormal reverse cerebral blood flow velocity (CBFV) was not investigated.

Diastolic flow reversal in CBFV has been described in patients with IABP [3]. This pattern implies negative CBFV in late diastole and has also been described in intracranial hypertension, brain death, and comatose patients [4]. However, the clinical significance of this dramatic alteration in the CBFV waveform pattern is still unknown.

We assessed the effect of CBFV reversal on CA, in patients with IABP, as part of a randomized clinical trial [2]. After ethical approval, we included patients submitted to elective cardiac surgery, who presented reverse CBFV and provided written informed consent.

CBFV (TCD) and intra-arterial blood pressure (BP) were performed over $5 \mathrm{~min}$ with the IABP operating a 1 : 3 ratio triggered by the electrocardiogram. Second measurement was performed for 5 min without pumping assistance soon after IABP was turned OFF.

CA was assessed by autoregulation index (ARI), with impaired CA defined as ARI $<4$ [2].

\footnotetext{
*Correspondence: ludhmila@usp.br; ludhmila@terra.com.br

${ }^{6}$ Department of Cardiopneumology, Universidade de São Paulo, São Paulo, Brazil

${ }^{7}$ Surgical Intensive Care, Heart Institute, University of São Paulo, Av. Dr. Enéas de Carvalho Aguiar 44, São Paulo 05403-000, Brazil

Full list of author information is available at the end of the article
}

Paired Student's $t$ test or Wilcoxon tests were used as appropriate.

Six of 34 patients with IABP presented CBFV reversal, aged $63.9 \pm 7.9$ years, EuroSCORE 5 [range 37], and echocardiogram LVEF 40\% [35-45].

$\operatorname{CBFV}(p=0.68)$ and BP $(p=0.08)$ did not show any differences between IABP-ON and IABP-OFF (Table 1).

For IABP-ON, ARI was 2.0 [0.0-5.6] and 4.5 [1.6-2.6] for IABP-OFF $(p=0.028)$.

Five patients showed impaired CA with IABP-ON; however, only 3 showed impaired CA with IABPOFF $(p=0.545)$. All patients increased the ARI on IABP-OFF, when compared with IABP-ON. None of the patients had a stroke or a diagnosis of brain injury, but two patients died and another two had delirium [2].

Our previous study found that IABP did not impair CA [2], but with CBFV reversal, we observed that CA was affected and the ARI increased in all patients when IABP was removed. This finding indicates that TCD can play an important role in the assessment of patients with IABP and we suggest a systematic approach for this purpose in Fig. 1. The main use of TCD in this context is to identify and manage the potential complications of CA impairment, to prevent the deleterious effects of changes in $\mathrm{BP}$, leading to ischemia or hyperperfusion [1].

CBFV reversal in IABP occurred in $17 \%$ of our cases, although it can occur in up to $35 \%$ of patients with IABP [3]. Reversal of diastolic CBFV at late diastole is probably due to rapid deflation of IABP [5], with the suggestion that CBFV reversal is iatrogenic and should be avoided. One possible approach is to optimize the balloon inflation/deflation cycle, by moving deflation to the absolute end of diastole [5]. The precise effects of CBFV reversal 
Table 1 Cerebral hemodynamic parameters and dynamic CA with IABP ON and IABP off

\begin{tabular}{|c|c|c|c|c|c|c|c|c|c|c|}
\hline \multirow[t]{2}{*}{ Patient number } & \multicolumn{4}{|c|}{$\begin{array}{l}\text { IABP } \\
\text { ON }\end{array}$} & \multirow[b]{2}{*}{$\mathrm{ETCO}_{2}(\mathrm{mmHg})$} & \multirow[b]{2}{*}{$\mathrm{ARI}^{\#}$} & \multirow[b]{2}{*}{$(\mathrm{mmHg})$} & \multicolumn{2}{|l|}{$\begin{array}{l}\text { IABP } \\
\text { OFF }\end{array}$} & \multirow[b]{2}{*}{$\mathrm{ETCO}_{2}(\mathrm{mmHg})$} \\
\hline & $\mathrm{ARI}^{\#}$ & $(\mathrm{mmHg})$ & HR (bpm) & $\begin{array}{l}\text { CBFV } \\
\text { MCA }(\mathrm{cm} / \mathrm{s})\end{array}$ & & & & HR (bpm) & $\begin{array}{l}\mathrm{CBFV} \\
\mathrm{MCA}(\mathrm{cm} / \mathrm{s})\end{array}$ & \\
\hline 25 & 0 & 84.9 & 86.6 & 87.9 & 32 & 1.6 & 81.6 & 84.7 & 88.1 & 32 \\
\hline 35 & 1.8 & 77.5 & 81.7 & 33.9 & 33 & 3.9 & 94.2 & 87.0 & 15.8 & 35 \\
\hline 65 & 2.3 & 67.3 & 121.2 & 80.4 & 35 & 5.1 & 63.9 & 123.8 & 85.6 & 35 \\
\hline 95 & 2.4 & 60.1 & 100.5 & 89.2 & 29 & 7.9 & 89.7 & 102.5 & 86.9 & 29 \\
\hline 96 & 1.6 & 43.1 & 96.2 & 91.4 & 38 & 3.9 & 81.3 & 90.3 & 95.1 & 38 \\
\hline 97 & 5.6 & 65.6 & 113.1 & 40.1 & 32 & 6.1 & 78.2 & 114.4 & 42.4 & 32 \\
\hline
\end{tabular}

$A R I$ autoregulation index, EtCO2 end- tidal CO2, MAP mean arterial pressure, $H R$ heart rate, $C B F V$ cerebral blood flow velocity, MCA middle cerebral artery ${ }^{\#} p<0.05$ (Wilcoxon tests) for the comparison between IABP ON and IABP OFF

on cerebral hemodynamics is still unknown; its departure from normal physiological waveforms likely to be undesirable and to have a negative effect on CA.

Furthermore, negative CBFV is a TCD pattern in brain death [4]. For this reason, in IABP patients with suspected brain-death, the IABP has to be on standby to allow determination of the main source of CBFV reversal (Fig. 1).
TCD is also important to detect microemboli in IABP (Fig. 1), a cause of cerebral infarct and commonly iatrogenic in origin, often reported in cardiothoracic surgery [6]. This complication in patients with IABP, when there is a rupture with gas embolization, is rare, but potentially fatal.

Larger studies are needed in IABP patients with reverse $\mathrm{CBFV}$ to assess their cerebral hemodynamics and neurological outcomes.

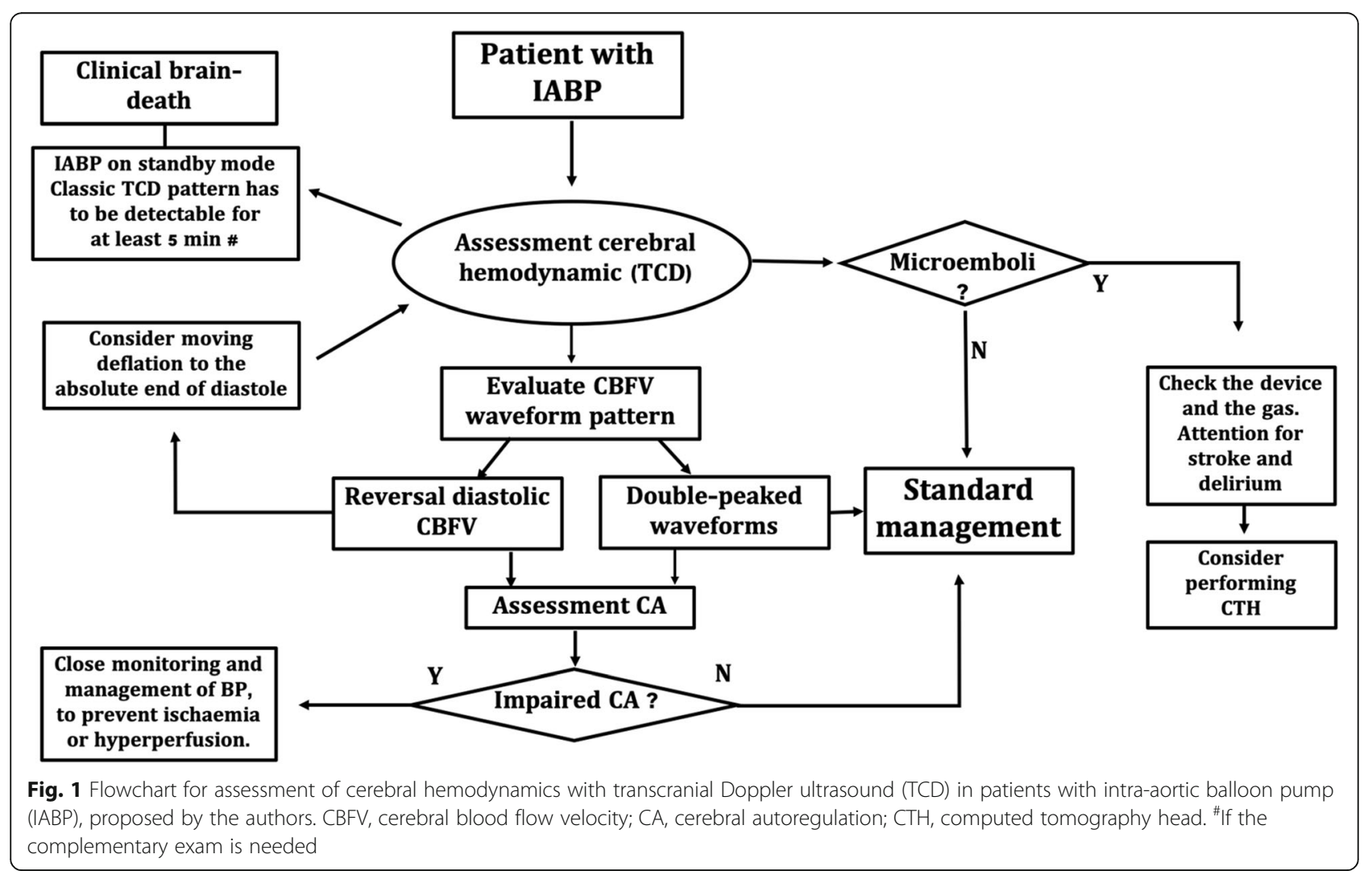




\section{Acknowledgements}

The participation of all patients is gratefully acknowledged.

\section{Authors' contributions}

JRC designed the study, performed the measurements and data analysis and interpretation, and drafted the manuscript. RBP wrote the software and supervised the data analysis and interpretation. RHP revised the final version of the manuscript. LAH designed the study and revised the final version of the manuscript. All authors checked the manuscript and approved the final version.

\section{Funding}

The study and the authors did not receive any financial support.

\section{Availability of data and materials}

All data generated or analyzed during this study are included in this published article its additional files.

\section{Ethics approval and consent to participate}

This study was approved by the local research ethics committee (approval number: 835.731), and written informed consent was provided of all subjects.

\section{Consent for publication}

Not applicable.

\section{Competing interests}

The authors declare that they have no competing interests.

\section{Author details}

${ }^{1}$ Critical Care Unit, Hospital São Rafael Rede DOR, Salvador, Brazil.

Universidade de Salvador- UNIFACS, Salvador, Brazil. ${ }^{3}$ Escola Bahiana de Medicina e Saúde Pública- EBMSP, Salvador, Brazil. ${ }^{4}$ Department of Cardiovascular Sciences, University of Leicester, Leicester, UK. ${ }^{5}$ NIHR Leicester Biomedical Research Centre, Leicester, UK. ${ }^{6}$ Department of Cardiopneumology, Universidade de São Paulo, São Paulo, Brazil. 'Surgical Intensive Care, Heart Institute, University of São Paulo, Av. Dr. Enéas de Carvalho Aguiar 44, São Paulo 05403-000, Brazil.

Received: 15 June 2020 Accepted: 4 October 2020

Published online: 23 October 2020

\section{References}

1. Robba C, Taccone FS. How I use transcranial Doppler. Crit Care. 2019;23:420.

2. Caldas JR, Panerai RB, Bor-Seng-Shu E, Ferreira GSR, Camara L, Passos RH, et al. Intra-aortic balloon pump does not influence cerebral hemodynamics and neurological outcomes in high-risk cardiac patients undergoing cardiac surgery: an analysis of the IABCS trial. Ann Intensive Care. 2019;9:130.

3. Schachtrupp A, Wrigge H, Busch T, Buhre W, Weyland A. Influence of intraaortic balloon pumping on cerebral blood flow pattern in patients after cardiac surgery. Eur J Anaesthesiol. 2005;22:165-70.

4. van der Naalt J, Baker AJ. Influence of the intra-aortic balloon pump on the transcranial Doppler flow pattern in a brain-dead patient. Stroke. 1996;27: $140-2$.

5. Gao YZ, Zhang M. Effect of intra-aortic balloon pump on reversal of diastolic cerebral flow: deflated too early? Neurocrit Care. 2018;29(2):313-4.

6. Grover G, Perera AH, Hamady M, Rudarakanchana N, Barras CD, Singh A, et al. Cerebral embolic protection in thoracic endovascular aortic repair. J Vasc Surg. 2018:68:1656-66.

\section{Publisher's Note}

Springer Nature remains neutral with regard to jurisdictional claims in published maps and institutional affiliations. 